\title{
Functional Outcome of Flexor Tendon Repair in Zone-II
}

\author{
Mostafa $\mathrm{MB}^{* 1}$, Mostafa $\mathrm{DG}^{2}$, Rahman $\mathrm{MM}^{3}$, Maula $\mathrm{MJ}^{4}$, Sultana $\mathrm{M}^{5}$, Haque $\mathrm{MM}^{6}$
}

${ }^{1}$ Dr. Md. Bayzid Mostafa, Senior Consultant, Department of Orthopaedic Surgery, Patuakhali 250 Bedded General Hospital, Patuakhali, Bangladesh

${ }^{2}$ Dr. Abu Daud Md. Golam Mostafa, Senior Consultant (Orthopaedics), District Hospital, Gaibandha, Bangladesh

${ }^{3}$ Dr. Md. Mahbubur Rahman, Residential Surgeon (Orthopaedics), M. Abdur Rahim Medical College Hospital, Dinajpur, Bangladesh

${ }^{4}$ Dr. Mustari Jahan Maula, Anaesthesiologist, Rangpur Medical College Hospital, Rangpur, Bangladesh

${ }^{5}$ Dr. Mamuni Sultana, MS Resident, Department of Gynae and Obstetrics, Dhaka Medical College, Dhaka, Bangladesh

${ }^{6}$ Dr. Md. Mahafil Haque, Assistant Professor, Department of Orthopaedics, M. Abdur Rahim Medical College, Dinajpur, Bangladesh

DOI: $10.36347 /$ sasjs.2021.v07i04.016

| Received: 12.03.2021 | Accepted: 24.04.2021 | Published: 30.04.2021

*Corresponding author: Dr. Md. Bayzid Mostafa

Abstract

Original Research Article

Introduction: Hand trauma and hand injury are quite common in our country. As a result of lack of safety in many workplaces, and an increased number of social and political violence, hand injuries are increasing every day. The basic functions of the hand are disturbed when the tendons are damaged. And proper repair is necessary to gain back full functions. Our country has a lack of qualified hand surgeons, so hand trauma patient has to suffer a lot here. This study focused on tendon repair in zone II, or "no man's land" of the hand, where the margin of error is extremely small due to having both tendons interweaved in a complex manner in this area. Before 1960, tendon injury was treated through secondary grafting, which was done after the primary wound had healed. After 1960, surgeons started to rely more on primary treatment for tendon repair. The aim of this study is to evaluate the functional outcome after primary repair of flexor tendons in zone II in sharp cut injury. Methods: This prospective quasi-experimental study was carried out at the National Institute of Traumatology and Orthopedic Rehabilitation (NITOR), Dhaka, during a 2-year timeframe, from January 2013 to November 2014. Result: Maximum of the patients were male and only 19\% were female. The majority of the patients belonged to the age group of 11-20 years. Index and ring fingers were the majority of the injured. There was a variety of occupations among the patients. $62.5 \%$ had injury in single digits. The majority of the injury was from a sharp cut from knife. The functional outcome was satisfactory in $67 \%$ of the cases, and most of the operations were done within 24 hours of the accident. Conclusion: The Flexor tendon repair in zone II is a challenging surgery. For satisfactory results, repair of all the tendons should be complete, eliminating all raw surfaces, but still allowing tendons to pass through the tunnel. This study shows that primary repair and early movement with passive flexion and active extension yields good results.

Keywords: Zone II, Flexor Tendon, Digits, Surgery, Adhesion, Functional Outcome.

Copyright $(\mathcal{C} 2021$ The Author(s): This is an open-access article distributed under the terms of the Creative Commons Attribution 4.0 International License (CC BY-NC 4.0) which permits unrestricted use, distribution, and reproduction in any medium for non-commercial use provided the original author and source are credited.

\section{INTRODUCTION}

Hand trauma is quite common in our country. Hospital statistics show that hand trauma with flexor tendon injuries is increasing day by day due to increased social and political violence all over the country. The hand is often called the "Third Eye:" due to its highly developed sensory mechanism that can give information about the height, size, and position of an object. The hand has three basic functions, sensory perception, precise manipulation, and power grip, carried by a musculotendinous unit. These functions can be greatly impaired if the flexor tendon is injured. For proper hand functions, intact tendons are a must. If flexor tendons are severed, then the affected fingers become functionless. Intact hand function is essential for most of the people of our country's livelihood, as most of them are workers. There is a lack of qualified hand surgeons in our country. For these, hand trauma patients, especially tendon injury patients have to suffer a lot. For injured flexor tendons, the main goal of surgery is the recovery of functionally acceptable digital motion. Verdan's classification is used to recognize Zone II for localization of site and tendon injury. ${ }^{[1]}$ It is called the "Zone II" or "No Man's Land" because of perennial anatomical characteristics, ${ }^{[2]}$ where both the tendons interweaved in a complex manner in the fibro-osseous digital canal. So, the margin of error in this zone is quite small, and any infection, fibrosis, cicatrix can lead to impairment of free motion in the 
tendons. The methods of hand surgery can be divided largely into two, before and after 1960. Before 1960, the use of was not that prevalent. Some of the prominent surgeons of that time preferred secondary grafting. According to Sterling Bunnel, the secondary procedure was performed after the wound healed, and included (a) Excising both the flexor tendon (b) Undertaking tendon grafting of the flexor digitorum profundus tendon only [2]. The satisfactory results started from 1960 when Kleinert submitted a report stating an astounding $87 \%$ Good to excellent results on the primary repair [3]. As a result, more new surgeons started to attempt primary repair, and hand therapists assumed a great role in the care of tendon injuries. No study on primary repair of Flexor Tendon was done in our country before this.

\section{OBJECTIVE \\ General Objective}

- To determine the functional outcome of hand after primary repair of the flexor tendon in zone II

\section{Specific Objectives}

- To find out the common complications after primary repair in zone II.

- To identify the mode of injury.

- To distribute the patients by age, sex, and occupation

\section{METHODOLOGY AND MATERIALS}

This was a prospective quasi-experimental study that was carried out in The National Institute of Traumatology and Orthopaedic Rehabilitation (NITOR), Dhaka. The study period was 2 years, from January 2013 to December 2014. The study was conducted with patients having flexor tendon injuries at Zone II of hand and those who had undergone repair within 7 days of Injury. Due to time constraints, the required sample size was not reached, and the current sample size was determined at 16 patients with a flexor tendon injury in a total of 27 fingers. Purposive sampling technique was used following the exclusion and inclusion criteria. A pre-designed proforma was used to collect data on the patients. The collected data was then compiled using SPSS software and using the appropriate formula.

\section{Inclusion Criteria}

- Age of injury less than one week.

- Age of the patient 12 to 50 years.

- Sharp cut injury along with FDP and FDS injury.

- Normal or near-normal passive range of motion of joints of fingers.

\section{Exclusion Criteria}

- Lacerated injury with extensive tear.

- Associated fracture of metacarpals and phalanges.

- Injury of both digital vessels and nerves where repair is a must.

\section{RESULTS}

The study was conducted with data regarding 16 sample patients and 27 fingers. The collected data was then illustrated and presented using graphs and tables. The age of the patients ranged from 17 to 38 years, with the mean age being $25.18 \pm 6.7$ years. The maximum number of patients $(43.75 \%)$ belonged to the age group of $11-20$ years, $31.25 \%$ belonged to the age group of 21-30 years and the remaining 4 were older than 30 years. Out of 16 patients, 13 were male and only 6 were female. This can be attributed to the fact that the male population has more outdoor work due to their occupations. Among the participants of this study, $25 \%$ of patients were service holders, $25 \%$ patients were laborers, $12.5 \%$ patients were housewives, $12.5 \%$ traders, $12.5 \%$ unemployed, 1(6.25\%) school teacher, and $1(6.25 \%)$ student. The majority of the involved fingers are ring fingers, $(33.33 \%)$, the index finger in $29.63 \%$ of cases, middle finger in $22.22 \%$ cases, and little finger in $14.41 \%$ cases. Figure III shows the mode of injury which caused tendon injury. Here maximum, $11(68.75 \%)$ patients sustained injury from a sharp knife, 4(25\%) patients suffered injury from broken glass, and 1(6.25\%) patients suffered injury from the sharp end of tin. Table III shows the distribution of patients according to the involvement of the number of digits. 10 patients had injury of only one finger and the remaining $37.5 \%$ patients had injury involving multiple fingers. This study was concluded with patients who were operated on within 7 days of injury. Maximum patients were operated on within the first 24 hours of injury, 1(6.25\%) patient was operated on the 3rd day, $2(12.5 \%)$ on the 4 th day, $2(12.5 \%)$ on the 5 th day, and $2(12.5 \%)$ on the 7 th day. Among the 16 patients and 27 digits, only 5 developed complications. 2 had ruptured tendons, 2 had developed an infection, and 3 developed adhesion formation. Table $\mathrm{V}$ shows the functional outcome of the digits with a minimum of 6 months of repair. $22.22 \%$ was recognized as excellent, $44.44 \%$ was recognized as good. $14.81 \%$ was regarded as fair and 18.52 was recognized as poor. In total, the results were satisfactory at $66.66 \%$ and poor at $33.34 \%$. The total follow-up period ranged from 5 months to 12 months, and the average was 8.62 months. Among the 16 patients, 2 were followed up for 5-6 months, 6 were followed up for 7-8 months, 5 for 9-10 months, and 3 for 11-12 months.

Table I: Distribution of patients according to age group $(n=16)$

\begin{tabular}{|l|l|l|}
\hline Age Group & $\mathbf{n}=\mathbf{1 6}$ & $\mathbf{n}(\boldsymbol{\%})$ \\
\hline $\mathbf{1 1 - 2 0}$ & 7 & 43.75 \\
\hline $\mathbf{2 1 - 3 0}$ & 5 & 31.25 \\
\hline $\mathbf{3 1 - 4 0}$ & 4 & 25 \\
\hline
\end{tabular}

$\mathrm{T}$ he age of the patients ranged from 17 to 38 years, with the mean age being $25.18 \pm 6.7$ years. Maximum number of patients $(43.75 \%)$ belonged to the age group of $11-20$ years, $31.25 \%$ belonged to the age 
group of 21-30 years and the remaining 4 were older than 30 years.

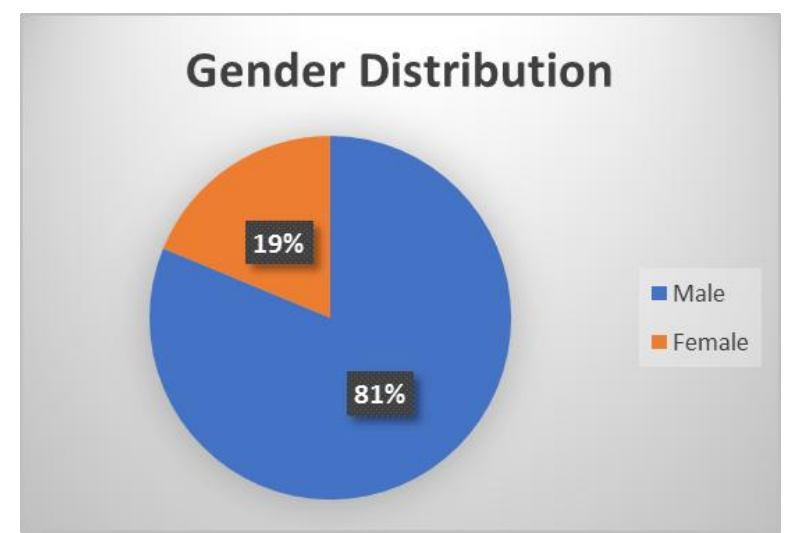

Fig. I: Gender distribution of patients $(n=16)$

Out of 16 patients, $81 \%$ were male and only $19 \%$ were female. This can be attributed to the fact that the male population has more outdoor work due to their occupations.

Table-2: Distribution of patients according to occupation $(n=16)$

\begin{tabular}{|l|l|l|}
\hline Occupation & $\mathbf{n}=\mathbf{1 6}$ & $\mathbf{n}(\boldsymbol{\%})$ \\
\hline Service Holder & 4 & 25 \\
\hline Labor & 4 & 25 \\
\hline House Wife & 2 & 12.5 \\
\hline Trader & 2 & 12.5 \\
\hline Unemployed & 2 & 12.5 \\
\hline School Teacher & 1 & 6.25 \\
\hline Student & 1 & 6.25 \\
\hline
\end{tabular}

In this study, $25 \%$ of patients were service holders, $25 \%$ patients were laborers, $12.5 \%$ patients were housewives, $12.5 \%$ traders, $12.5 \%$ unemployed, $1(6.25 \%)$ school teacher, and 1(6.25\%) student.

\section{Involved Fingers}

$$
\begin{aligned}
& 50
\end{aligned}
$$

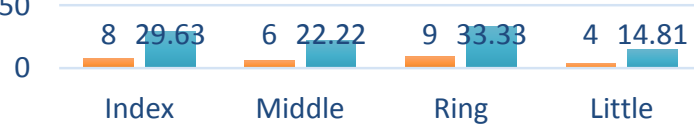

$$
\begin{aligned}
& \text { - } \mathrm{n}=27 \text { n(\%) }
\end{aligned}
$$

Fig-2: Distribution of Involvements of the finger $(n=27)$

In this study, majority of the involved fingers are ring fingers, $(33.33 \%)$, the index finger in $29.63 \%$ of cases, middle finger in $22.22 \%$ cases and little finger in $14.41 \%$ cases.

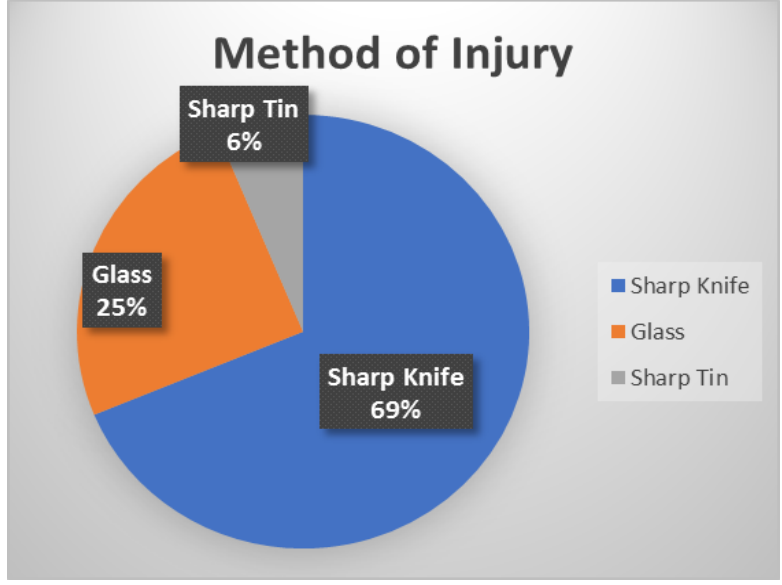

Fig-3: Distribution of Methods of Injury $(n=16)$

Figure 3 shows the mode of injury that caused tendon injury. Here maximum, 11(68.75\%) patients sustained injury from a sharp knife, $4(25 \%)$ patients suffered injury from broken glass, and 1(6.25\%) patients suffered injury from the sharp end of tin.

Table-3: Distribution of patients according to Number of involved digits $(n=16)$

\begin{tabular}{|l|l|l|}
\hline Involvement of Fingers & $\mathbf{n = 1 6}$ & $\mathbf{n}(\boldsymbol{\%})$ \\
\hline Single & 10 & 62.5 \\
\hline Multiple & 6 & 37.5 \\
\hline
\end{tabular}

Table 3 shows the distribution of patients according to the involvement of number of digits. 10 patients had injury of only one finger and the remaining $37.5 \%$ patients had injury involving multiple fingers.

\section{TIME INTERVAL OF OPERATION}

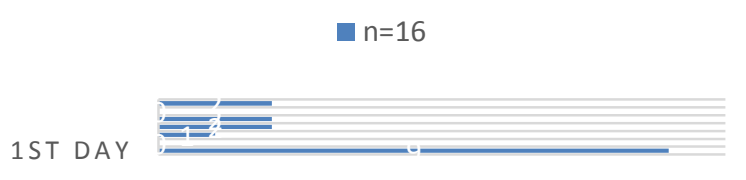

Fi- 4: Distribution of Methods of Injury $(n=16)$

This study was concluded with patients who were operated on within 7 days of injury. Maximum patients were operated on within the first 24 hours of injury, $1(6.25 \%)$ patient was operated on the $3 \mathrm{rd}$ day, $2(12.5 \%)$ on the 4 th day, $2(12.5 \%)$ on the 5 th day, and $2(12.5 \%)$ on the 7 th day.

Table 4: Distribution of digits by complication

\begin{tabular}{|l|l|l|}
\multicolumn{1}{|c}{$(\mathbf{n}=\mathbf{2 7})$} \\
\hline Complications & $\mathbf{n = 2 7}$ & $\mathbf{n}(\%)$ \\
\hline Rupture & 2 & 7.41 \\
\hline Infection & 2 & 7.41 \\
\hline Adhesion & 3 & 11.11 \\
\hline
\end{tabular}


Among the 16 patients and 27 digits, only 5 developed complications. 2 had ruptured tendons, 2 had developed an infection, and 3 developed adhesion formation.

Table-5: Functional outcome of digits $(n=27)$

\begin{tabular}{|l|l|l|}
\hline Functional Outcome & $\mathbf{n = 2 7}$ & $\mathbf{n}(\boldsymbol{\%})$ \\
\hline Excellent & 6 & 22.22 \\
\hline Good & 12 & 44.44 \\
\hline Fair & 4 & 14.81 \\
\hline Poor & 5 & 18.52 \\
\hline
\end{tabular}

Table 5 shows the functional outcome of the digits with a minimum of 6 months of repair. $22.22 \%$ was recognized as excellent, $44.44 \%$ was recognized as good. $14.81 \%$ was regarded as fair and 18.52 was recognized as poor.

Table-6: Time of follow up in patients $(n=16)$

\begin{tabular}{|l|l|l|}
\hline Time of Follow Up (month) & $\mathbf{n = 1 6}$ & $\mathbf{n}(\boldsymbol{\%})$ \\
\hline $\mathbf{5 - 6}$ & 2 & 12.5 \\
\hline $\mathbf{7 - 8}$ & 6 & 37.5 \\
\hline $\mathbf{9 - 1 0}$ & 5 & 31.25 \\
\hline $\mathbf{1 1 - 1 2}$ & 3 & 18.75 \\
\hline
\end{tabular}

The total follow-up period ranged from 5 months to 12 months, and the average was 8.62 months. Among the 16 patients, 2 were followed up for 5-6 months, 6 were followed up for 7-8 months, 5 for 9-10 months, and 3 for 11-12 months.

\section{DISCUSSION}

Flexor tendon injury at zone II of hand has always presented as a problem in the management. There is no fixed method of treatment for this injury. In most cases, the injury involves both tendons, which can cause significant morbidity to patients due to loss of grip and other functions if not repaired properly. In Bangladesh, this type of injury is mainly seen in the earning members of the family, often in form of deep cuts. As the earning members of the family, they need early treatment and proper management to have a speedy return to their workplace. But to achieve a fully functional repair, the procedure and aftercare are extremely lengthy. In cases of injury with minimal tissue laceration, the primary repair is the method of choice for the surgeons, considering the patient is found immediately, and early mobilization is possible. In this study, an early passive mobilization program was practiced, which allows tendon healing by tendon softening, adhesion formation, and decreasing oedema. In this study, the age of the patients varied from a minimum of 17 years to a maximum of 38 years. Among the patients, a maximum of 7 was from the 1220 years age group, and the mean age was $25.18 \pm 6.7$ years. Similar data were found in multiple other studies. Though the age range was somewhat different, a study conducted in 1977, 1980, and 1989 had a mean age of 24 years, 24.6 years, and 21 years respectively[4,5,6]. people from the younger age group are affected more as a result of their high involvement in outdoor activity. The age of the patient is also an important factor in reaching a satisfactory outcome. In this study, of the 5 unsatisfactory (poor + rupture) cases, 4 patients were older than 30 years. This indicates that younger patients have a better outcome compared to older patients. There were $81 \%$ male and $19 \%$ female participants in this study. This corresponds with a study by Silfverskiold \& May, where the male and female percentage was $80 \%$ and $20 \%$ respectively[7]. Another study conducted in 1987 had similar results as well [8]. But the malefemale ratio was somewhat different in another study, while the male participants were still higher than the female participants [6]. This can be explained by the fact that in many societies, the major working force is male, and as a result, face a more external environment. This is more apparent in Bangladesh where the men work outside in various fields and the majority of the women work as housewives. Incidence of involved digit shows that index finger was involved in $29.63 \%$ of cases, the middle finger was involved in $22.22 \%$ cases, ring finger in $33.33 \%$ cases, and little finger in $14.8 \%$ cases. Comparing with other studies, different rate of involvement was found in different studies, and no clear connection was made $[9,10,11]$. There were few cases of flexor tendon injury of the thumb in our study, but none fulfilled the inclusion criteria. $68.75 \%$ of the study had an injury from a cut due to a sharp knife, $25 \%$ had cut tendons by sharp broken glass, and 1 patient had cut injury from tin. Another study conducted in 1993 also showed that $60 \%$ of patients had a sharp cut injury, but the remaining $26.66 \%$ had cut from machine saw and $13.33 \%$ had compression cut injury. This did not correspond with our study but can be explained by their high industrialization and social security. Our study showed that the majority of the patients got trauma from occupational work, $37 \%$ had accidents during housework and $19 \%$ had suffered physical assault. Although there are many daily activities in our life that require handling of sharp objects, safety measures are not properly taken all the time. Occupational safety is also hard to come by in many industries. The current study showed that people from different occupations can suffer tendon injury, as we had $25 \%$ service holders, $25 \%$ laborers, $12.5 \%$ traders, $12.5 \%$ housewives, $12.5 \%$ unemployed, and even 1 teacher and 1 student. This study only included participants who had an operation within the first week of the injury. Of them, $56 \%$ were operated on within the first 24 hours, 1 patient was operated on the $3^{\text {rd }}$ day of injury, and 2 patients each were operated on the $4^{\text {th }}, 5^{\text {th, }}$ and $7^{\text {th }}$ day of injury. Early operation in the 9 cases was possible due to the fact that patients came on the day of the injury and a hand surgeon was available to repair. As an expert and experienced surgeons are needed to perform zone II tendon repair, the operation was delayed if the hand surgeon with proper expertise was not available. There were also some cases where tendon injury by sharp cut was seen as a simple skin laceration 
by non-qualified medical practitioners, and the patients came to us after they were unable to flex their fingers after skin closure. The range of follow-up was 5 months to 12 months, with an average being 8.62 months. Functional outcome was satisfactory (excellent + good) in $67 \%$ of the fingers, and unsatisfactory (fair + poor + rupture) in $33 \%$ of the cases. The failure rate (poor + rupture) was $18 \%$. Somewhat different results were found in other studies, wherein in a study in 1983, the satisfaction rate was $75 \%$ [12]. Another study in 1980 showed a $56 \%$ satisfaction rate, where passive flexion and active extension with a palmar pulley were practiced [5]. Although the difference is statistically nonsignificant, similar rates of success were found in some other studies as well [3, 10, 11, 13] 2 patients in this study had tendon rupture both within 2 weeks of repair. The cause was later determined as an accidental passive extension. The rupture rate was $7.4 \%$ in this study. Some other studies had lower rupture rates, which might be attributed to their high level of expertise and good supervised physiotherapy system [3, 14]. Previously it was believed that adhesion to the surrounding soft tissue is a must for flexor tendon healing, but the current knowledge tells us that it serves no purpose in flexor tendon healing and is only used to severely restrict tendon gliding [15].

\section{Limitations of the study}

The major complications faced during this study were the extremely small sample size and a relatively short time of follow-up. Lack of a control group was also a complication.

\section{CONCLUSION}

The Flexor tendon repair in zone II is always challenging. For satisfactory results, repair of all the tendons should be complete, eliminating all raw surfaces, but still allowing tendons to pass through the tunnel. This study shows that primary repair and early movement with passive flexion and active extension yields good results.

\section{RECOMMENDATION}

The sample size needs to be increased, and the study needs to have a control group as well. All operations should be done within 24 hours, and physiotherapy should be done by a specialized hand therapist.

\section{Funding Source: Self}

\section{Conflict of interest: None Declared.}

\section{REFERENCES}

1. Verdan CE. Primary repair of flexor tendons. JBJS. 1960 Jun 1; 42(4):647-57.
2. Bunnell ST. Surgery of the hand, 3 rd edn. Philadelfhia.

3. Lister GD, Kleinert HE, Kutz JE, Atasoy E. Primary flexor tendon repair followed by immediate controlled mobilization. The Journal of Hand Surgery. 1977 Nov 1; 2(6):441-51.

4. Lister GD, Kleinert HE, Kutz JE, Atasoy E. Primary flexor tendon repair followed by immediate controlled mobilization. The Journal of Hand Surgery. 1977 Nov 1; 2(6):441-51.

5. Strickland JW, Glogovac SV. Digital function following flexor tendon repair in zone II: a comparison of immobilization and controlled passive motion techniques. The Journal of hand surgery. 1980 Nov 1; 5(6):537-43.

6. Small JO, Brennen MD, Colville J. Early active mobilisation following flexor tendon repair in zone 2. The Journal of Hand Surgery: British \& European Volume. 1989 Nov 1; 14(4):383-91.

7. Silfverskiöld KL, May EJ. Flexor tendon repair in zone II with a new suture technique and an early mobilization program combining passive and active flexion. The Journal of hand surgery. 1994 Jan 1; 19(1):53-60.

8. Chow JA, Thomes LJ, Dovelle SO, Milnor WH, Seyfer AE, Smith AC. A combined regimen of controlled motion following flexor tendon repair in" no man's land". Plastic and Reconstructive Surgery. 1987 Mar 1; 79(3):447-55.

9. May EJ, Silfverskiöld KL, Sollerman CJ. Controlled mobilization after flexor tendon repair in zone II: a prospective comparison of three methods. The Journal of hand surgery. 1992 Sep 1; 17(5):942-52.

10. Savage R, Risitano G. Flexor tendon repair using a "six strand" method of repair and early active mobilisation. Journal of Hand Surgery. 1989 Aug;14(4):396-9.

11. Baktir A, Türk CY, Kabak Ş, Şahin V, Kardaş Y. Flexor tendon repair in zone 2 followed by early active mobilization. Journal of Hand Surgery. 1996 Oct;21(5):624-8.

12. Lister GD. Incision and closure of the flexor sheath during primary tendon repair. Hand. 1983 Jun (2):123-35.

13. Cullen KW, Tolhurst P, Lang D, Page RE. Flexor tendon repair in zone 2 followed by controlled active mobilisation. Journal of Hand Surgery. 1989 Aug; 14(4):392-5.

14. Chow JA, Thomes LJ, Dovelle S, Monsivais J, Milnor WH, Jackson JP. Controlled motion rehabilitation after flexor tendon repair and grafting. A multi-centre study. The Journal of bone and joint surgery. British volume. 1988 Aug;70(4):591-5.

15. Potenza AD. Tendon healing within the flexor digital sheath in the dog: an experimental study. JBJS. 1962 Jan 1; 44(1):49-64. 